\title{
SEJARAH DAN TANTANGAN INDONESIA KONTEMPORER
}

Shohibul Anshor Siregar 


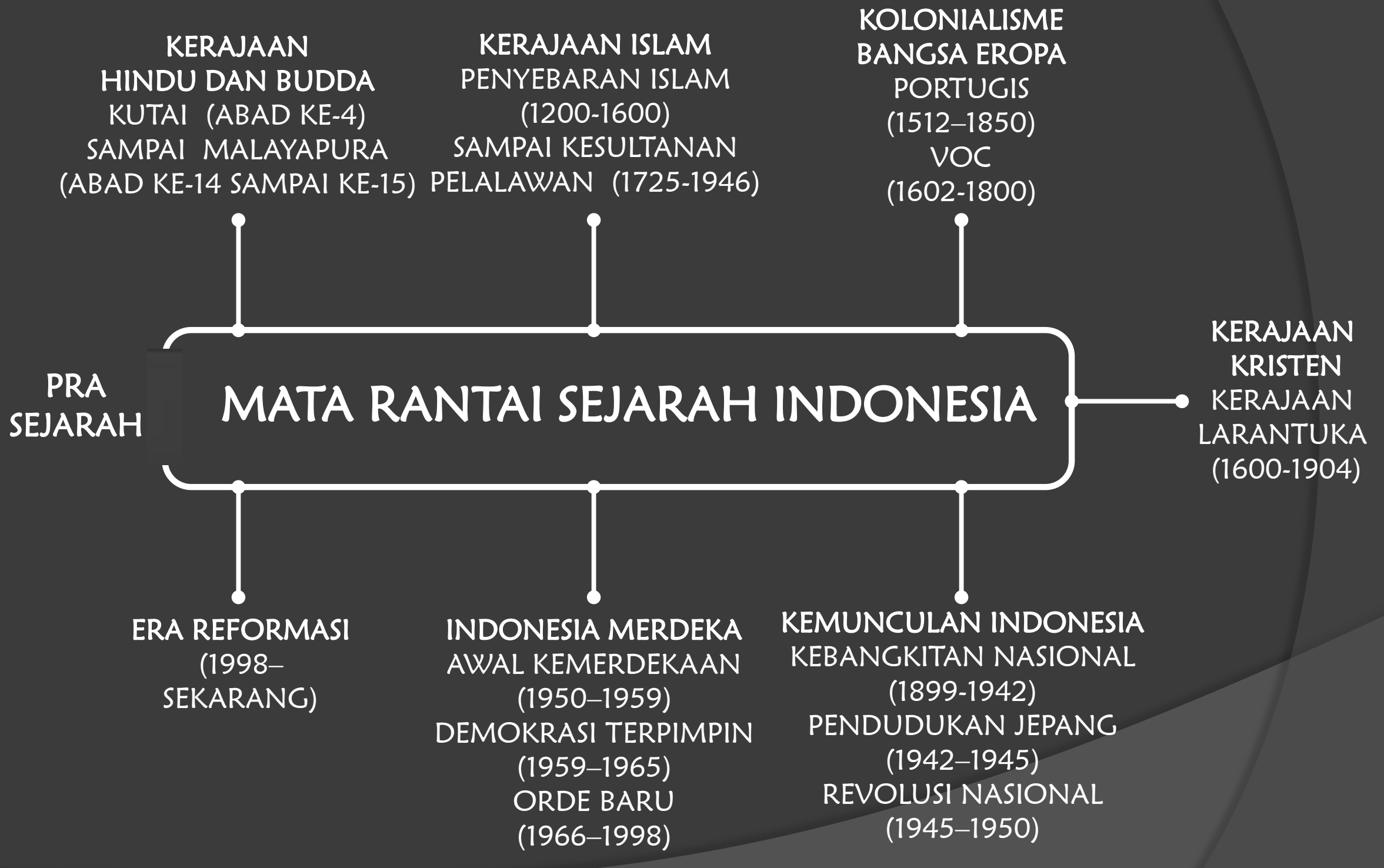




\section{BERBAGAI FAHAM DALAM SEJARAH INDONESIA}

KOLONIALISME BARAT

$\downarrow$

\section{\begin{tabular}{l|l} 
KRISTEN & SOSIALISME \\
DEMOKRAT
\end{tabular}}

KOMU-

NISME

\& PKI

\section{NASIONA-} LISME RADIKAL,

PNI

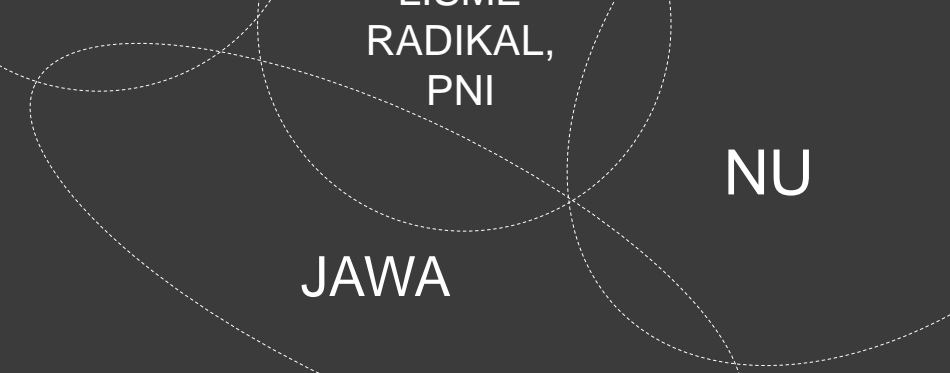

ISLAM

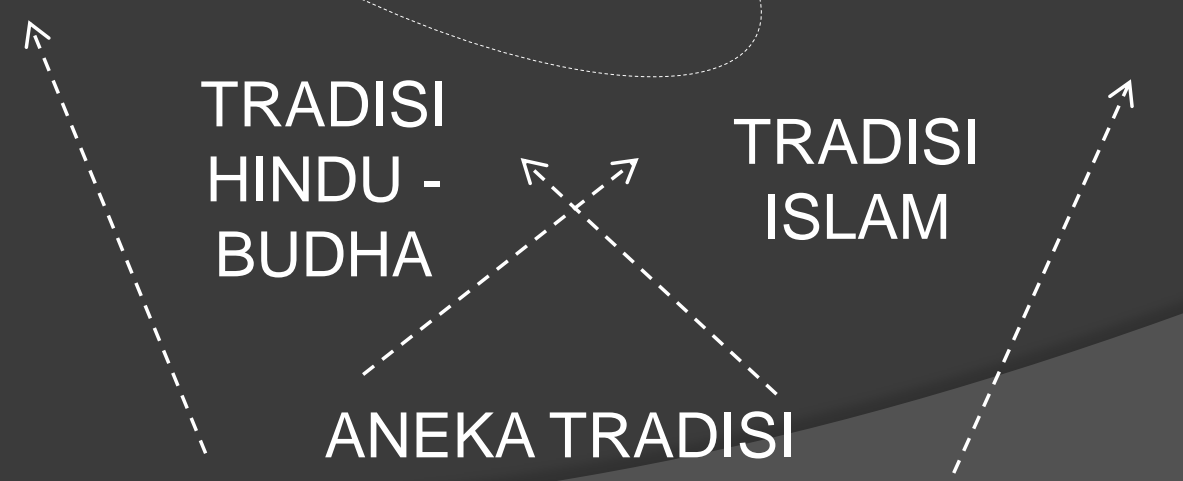




\section{SEJARAH KONSTITUSI KITA}

Masa transisi

Revolusi fisik

Yang belum

tuntas

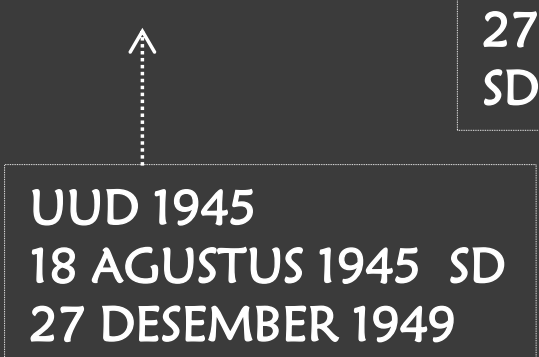

\section{Konstituante telah}

bersidang 2,5 tahun.

Bung Karno menilai

perlu melakukan dekrit.

Dampaknya ialah

Hanya 3 dari 16

Negara bagian

yang patuh kepada

Pemerintah pusat

(Negara Republik

Indonesia, Indonesia

Timur danSumatera

Timur)

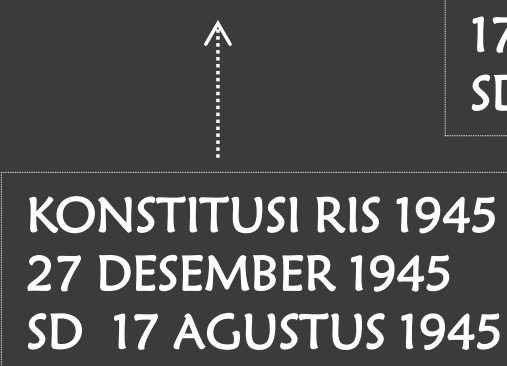

bahwa dirinya

menjadi penguasa

yang jauh dari

aroma demokrasi

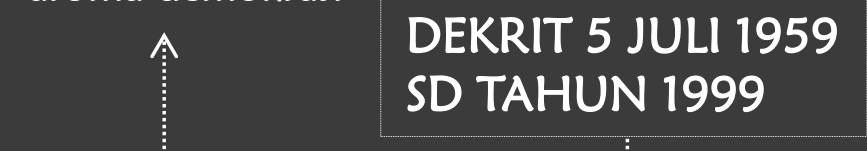

UUDS 1950

17 AGUSTUS 1950

SD 5 JULI 1959
UUD NRI TAHUN 1945 HASIL AMANDEMEN

(4 KALI)

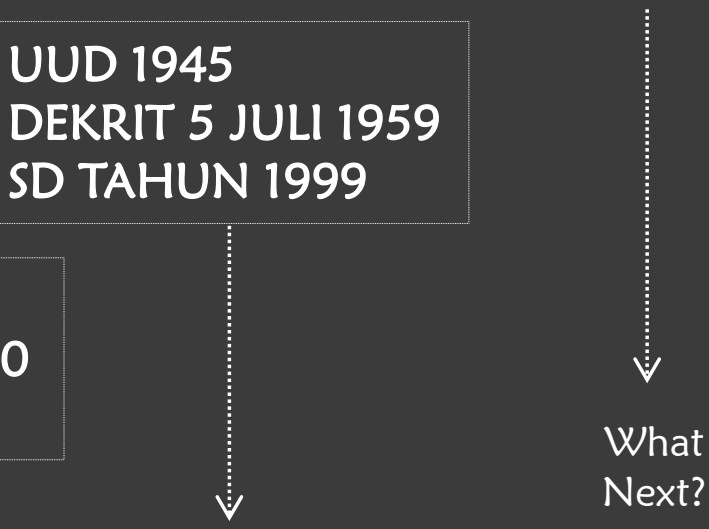

Tuntutan Reformasi:

(1) Amandemen UUD

(2) Hapus Dwi-fungsi ABRI

(3) Penegakan Hukum, HAM, dan pemberantasan KKN

(4) Otonomi Daerah

(5) Kebebasan Pers

(6) Meninjau ulang kehidupan demokrasi 


\section{PRISMATIC SOCIETY (RIGGS)}

BERHARAP ELIT NASIONAL TIDAK GAGAL MENGENDALIKAN PERUBAHAN

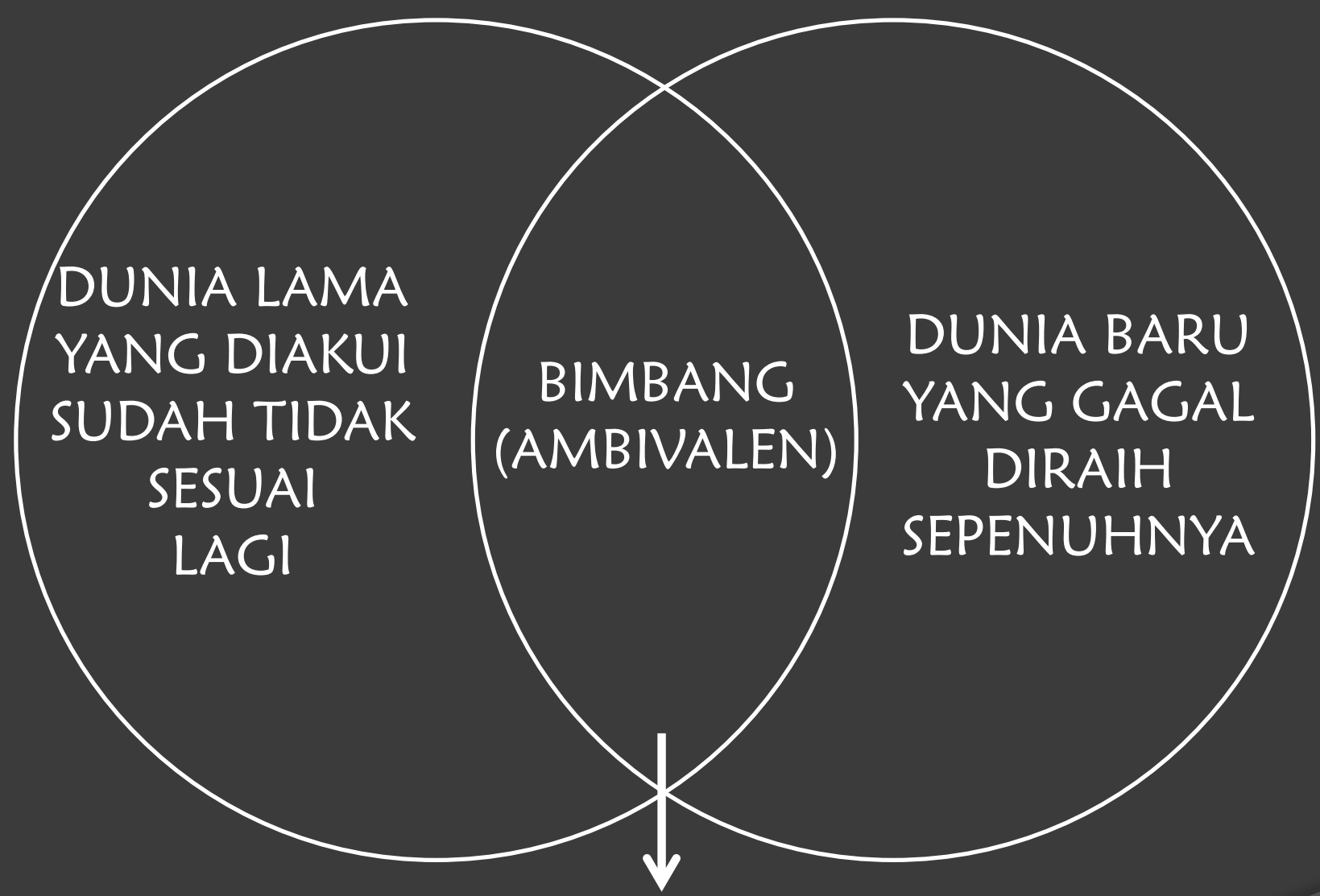

ANOMALI, STANDAR MORAL GOYAH, PERUBAHAN BISA MENGHASILKAN REGRESS YANG LEBIH BESAR KETIMBANG PROGRESS 



\section{PANCASILA}

Semakin baik atau semakin burukkah kondisi masyarakat Indonesia dalam

hal:

\section{Semakin baik Semakin buruk Tetap Tidak tahu}

(dalam persen)

Percaya dan takwa kepada Tuhan YME

\begin{tabular}{|ll|l|l|}
\hline 38,2 & 11,5 & 47,7 & 2,6
\end{tabular}

Hormat-menghormati antar pemeluk agama

\begin{tabular}{l|l|l|l}
\hline 53,6 & 19,1 & 26,2 & 1,1
\end{tabular}

Tenggang rasa dengan orang lain

\begin{tabular}{|l|l|l|l|}
\hline 44,9 & 17,4 & 36,8 & 0,9
\end{tabular}

JAJAK PENDAPAT TAHUN 2015
Menjunjung tinggi nilai kemanusiaan

\begin{tabular}{l|l|l|l|}
\hline 39.6 & 38,1 & 39,2 & 3,1
\end{tabular}

Persatuan bangsa di atas kepentingan golongan

\begin{tabular}{l|l|l|l|}
\hline 30,8 & 17,6 & 48,9 & 2,7
\end{tabular}

Berkorban untuk kepentingan bangsa

\begin{tabular}{l|l|l|l}
\hline 34,1 & 21,9 & 40,6 & 3,4
\end{tabular}

Mengutamakan musyawarah dalam membuat keputusan

\begin{tabular}{|c|c|c|c|}
\hline 42,3 & & 17,2 & 37,3 \\
\hline \multicolumn{4}{|c|}{ Keadilan Ekonomi } \\
\hline 16,5 & 19,1 & & 60,9 \\
\hline \multicolumn{4}{|c|}{ Keadilan Hukum } \\
\hline 20,1 & 17,0 & & 58,9 \\
\hline
\end{tabular}

Sudah sesuai dengan nilai-nilai Pancasila atau belumkah pelaksanaan kebijakan pemerintahan terkait hal-hal berikut ini:

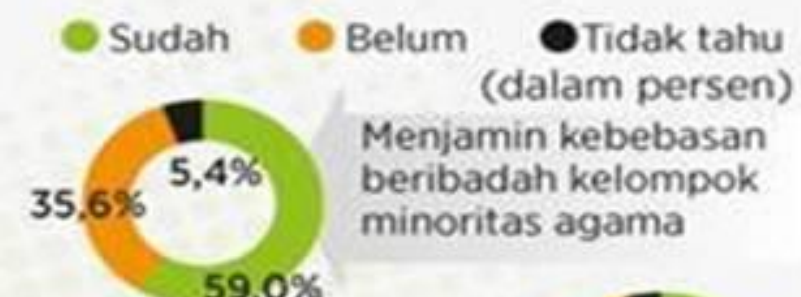

Melaksanakan penegakan hukum tanpa tebang pilih

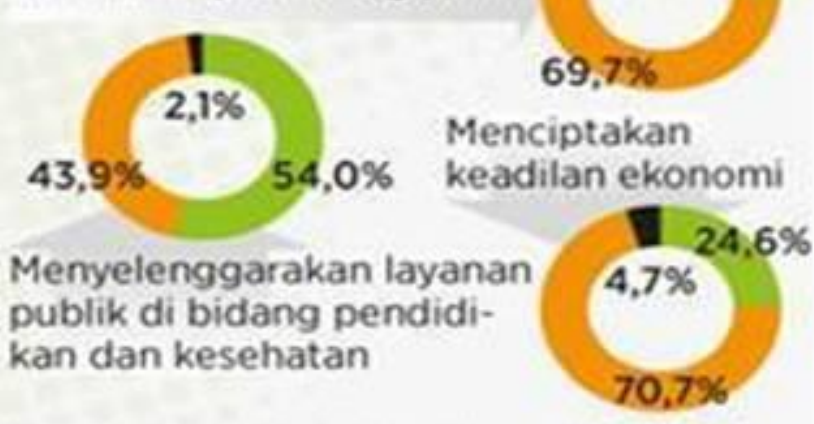

Sudah sesuai dengan nilai-nilai Pancasila atau belumkah sikap dan perilaku elite-elite politik selama ini dalam menyelesaikan persoalan bangsa?

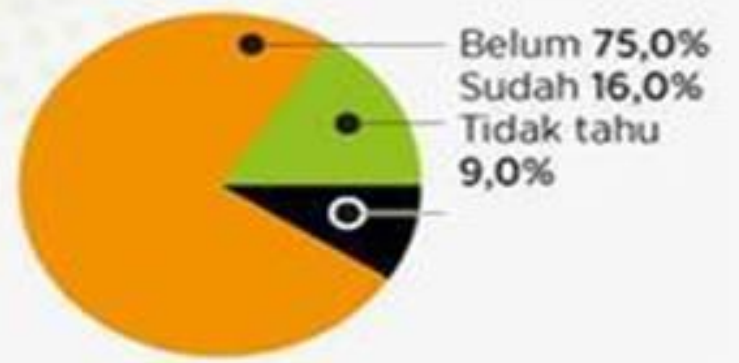


Percaya atau tidakbh Anda jika dikatakan bahwa Pancasila adalah ideologi yang paling baik bagi bangsa Indonesia? (balas pecoes bulatho)

\begin{tabular}{|c|c|c|c|c|c|c|}
\hline Percaya & 90 & 95 & 89 & 92 & 98 & \\
\hline Tidak percaya & 8 & 3 & 7 & 7 & 1 & 6 \\
\hline Tidak tahu/tidak jawab & 2 & 2 & 4 & 1 & 1 & 1 \\
\hline & 008 & 2009 & 2010 & 2011 & 2014 & 2015 \\
\hline
\end{tabular}

Metode Late Prodxat

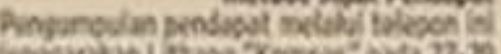

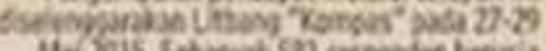

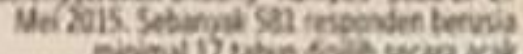

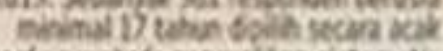

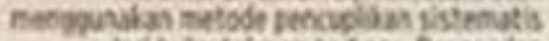

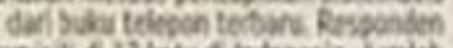

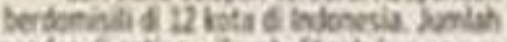

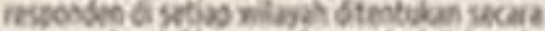

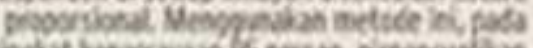

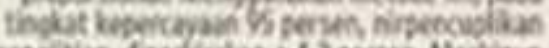

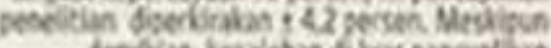

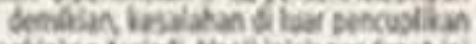

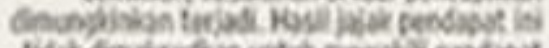

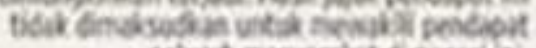

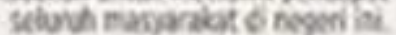

Kuat atau lemahkah pelaksanaun nilai-nilai Pancasila di dalam lembaga ini? (Galas pernew)

\begin{tabular}{|c|c|c|c|}
\hline teveras & nut & LENA & $\begin{array}{l}\text { nodx tark } \\
\text { noureswas }\end{array}$ \\
\hline OPR & 18.2 & 73.3 & 18.5 \\
\hline Partai Politik & [EST & 73.8 & 111 \\
\hline Kepolisian & 305 & 60,6 & 189 \\
\hline TNI & 577 & 28,2 & 143 \\
\hline Kejaksaan & 25,1 & 61,3 & 13.6 \\
\hline Kehakiman & $20 !$ & 62.1 & 138 \\
\hline Kabinet & 522 & 53.7 & 14.3 \\
\hline KPK & $\mathbf{8 B . 7}$ & 38.0 & 13,3 \\
\hline
\end{tabular}

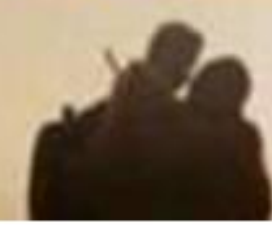

Hal-hal yang paling berpotensi merusak/mengancam keberadaan Pancasila sebagai dasar negara saat ini (culan persen)

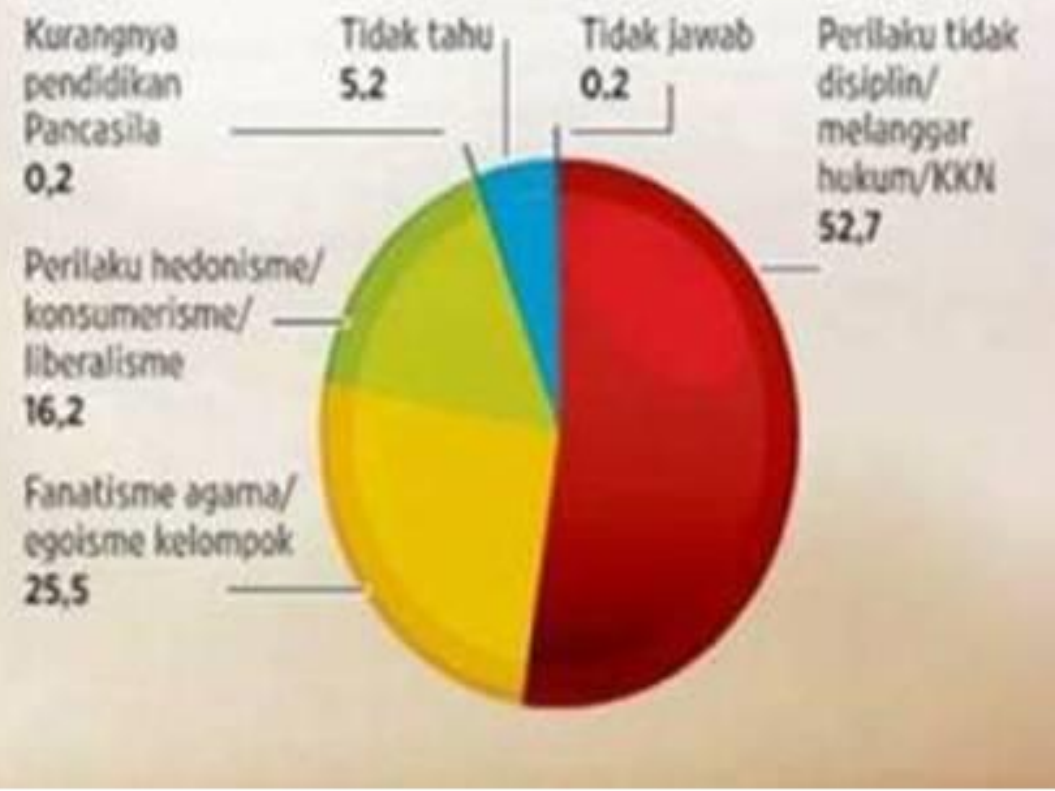

JAJAK PENDAPAT

TAHUN 2015 
KONGRES PANCASILA 1 S.D. 8 :

GERAKAN KEMBALI KE DASAR

MENEGUHKAN, MEREAKTUALISASIKAN, DAN MEREVITALISASI KAN NILAI-NIAI PANCASILA MENUJU TERWUJUDNYA INDONESIA YANG MODERN, DEMOKRATIS PA ADIL DAN SEJAHTERA

KONGRES PANCASILA 1 UGM (2009)
Disarikan dari berbagai sumber: SAS, "nBASIS

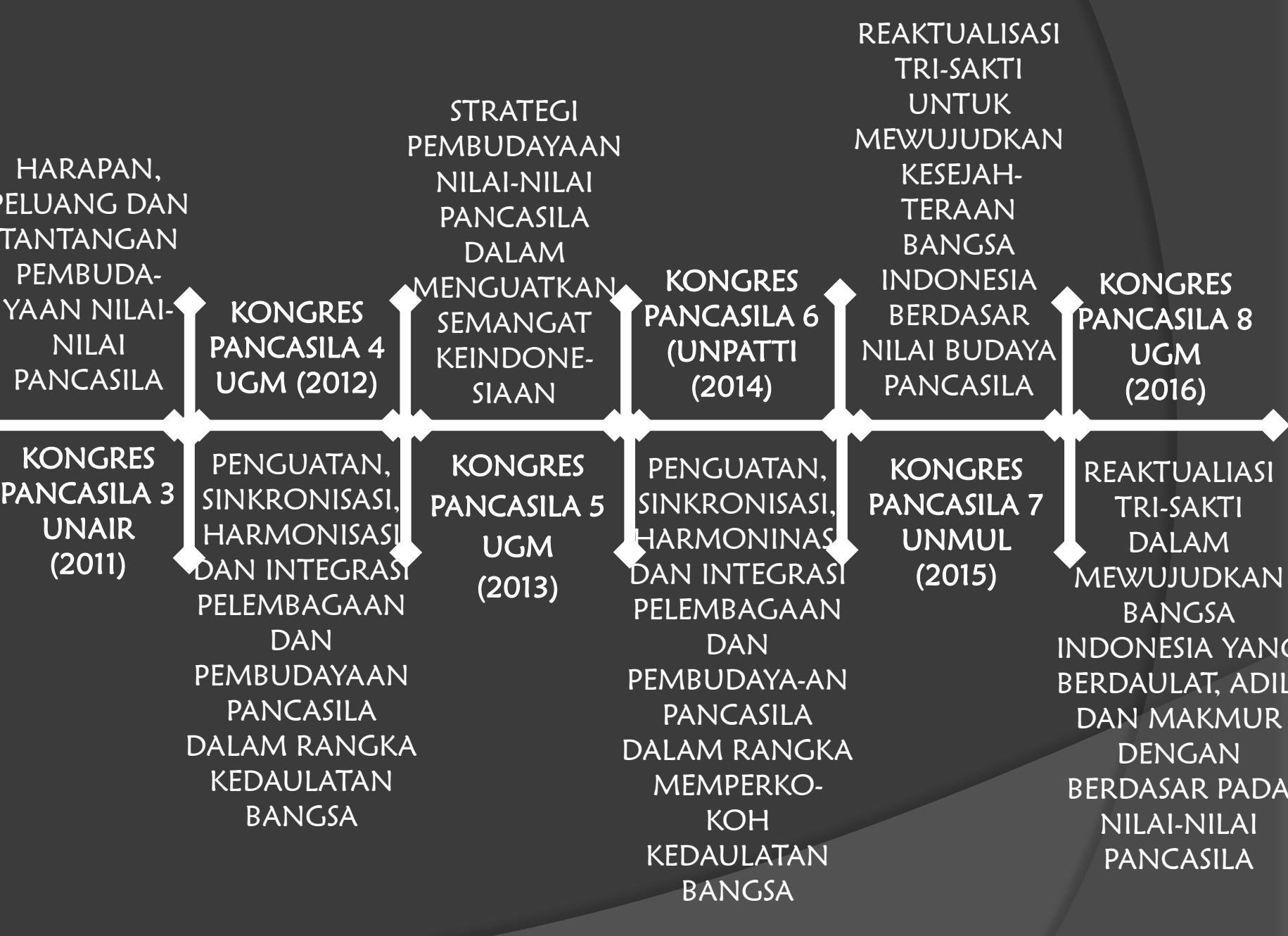





\section{KETIMPANGAN EKONOMI INDONESIA PERINGKAT 4}

Ketimpangan orang kaya dan miskin di Tanah Air masih tinggi. Ini tercermin dari akumulasi kekayaan segelintir warga yang menguasai kekayaan nasional dan simpanan perbankan. Bahkan lembaga keuangan Swiss, Credit Suisse menempatkan Indonesia di urutan keempat dengan disparitas kekayaan tertinggi.

\section{NEGARA DENGAN KESENJANGAN TERTINGGI}

Persentase kekayaan nasional yang dimiliki oleh 1 persen warga.

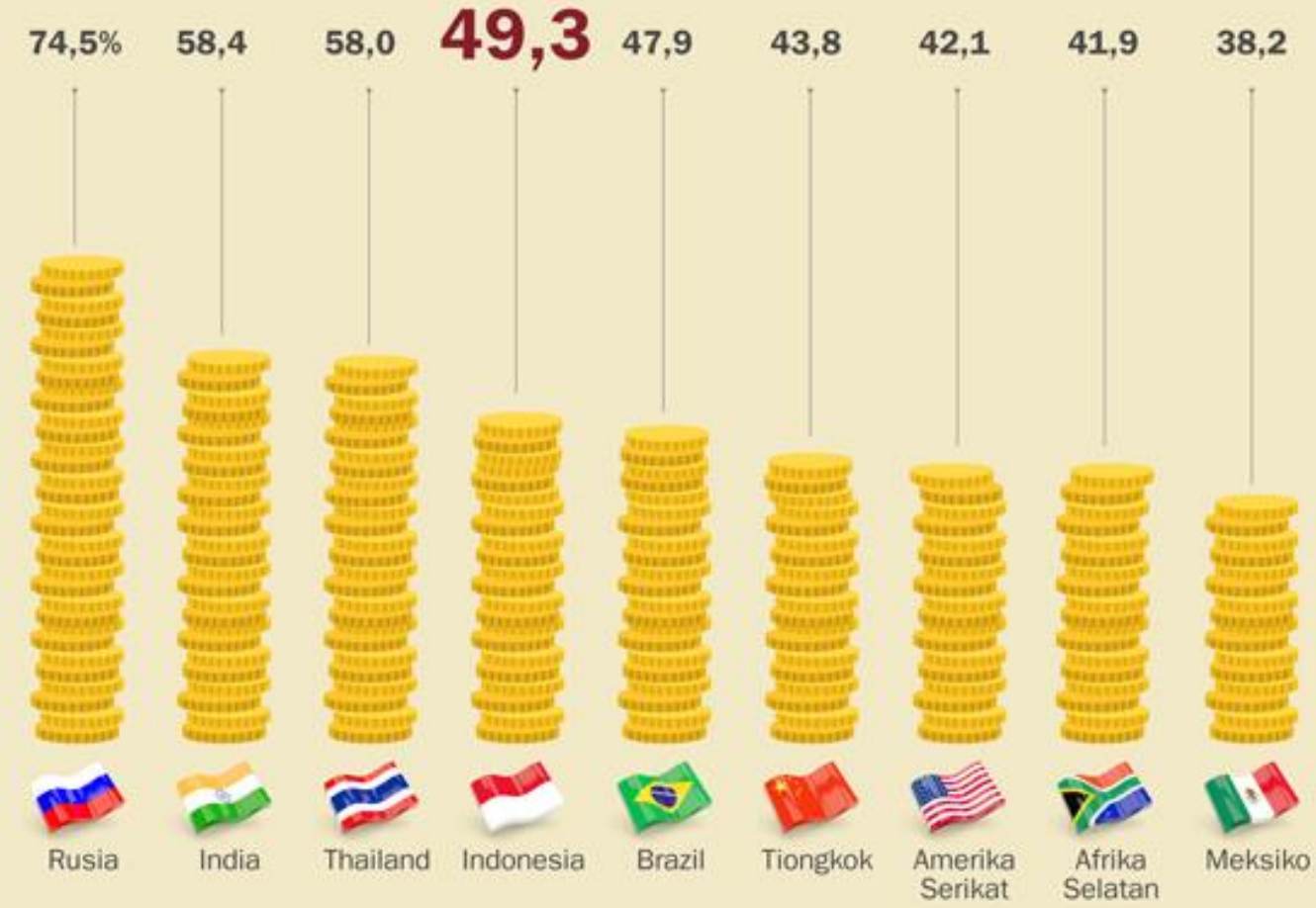

INDEKS KETIMPANGAN MASIH JAUH DARI TARGET

Jurang antara si kaya dan miskin di Indonesia masih tinggi. Dari target 0,36. Gini Ratio Indeks masih di angka 0,397 pada Maret 2016.

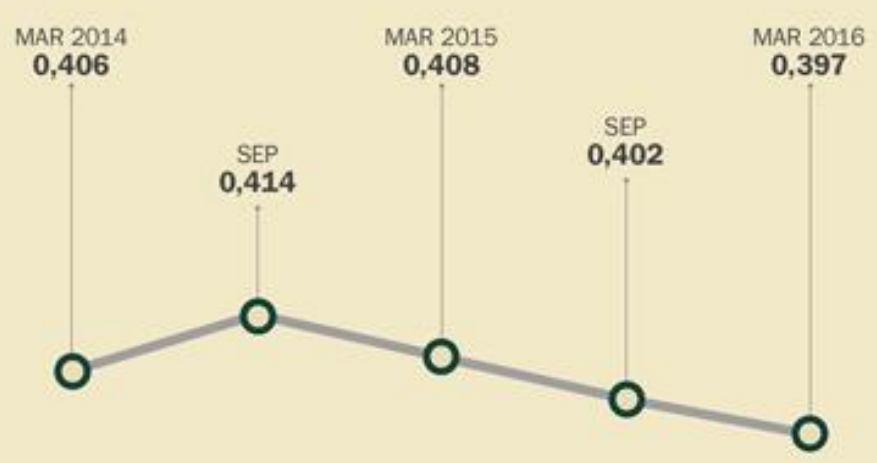

\section{PERBANKAN NASIONAL DIKUASAI PEMILIK REKENING DI ATAS 2 MILIAR}

Rekening di atas Rp 2 miliar Kurang dari Rp 100 Juta

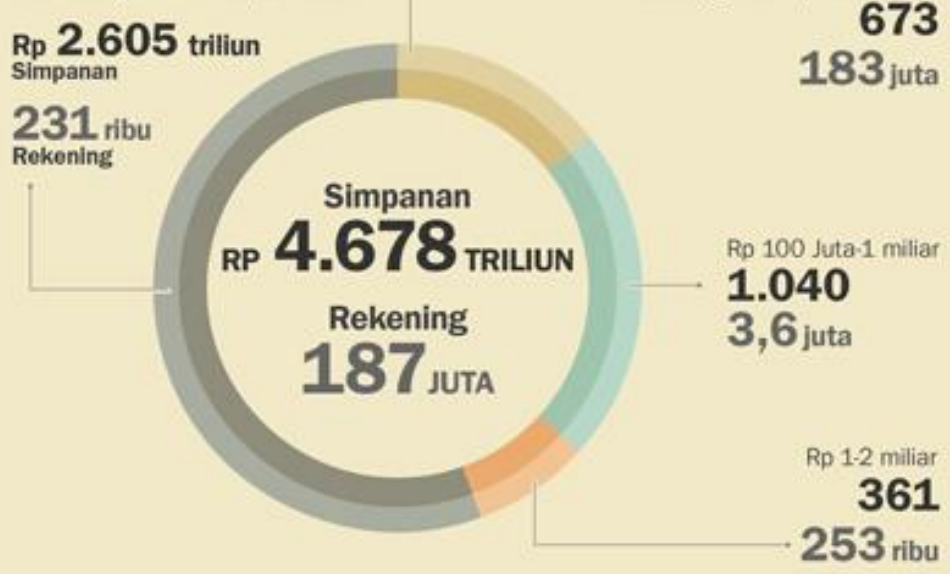




\section{PROFIL KEMISKINAN DI INDONESIA MARET 2017}

Berita Resmi Statistik No. 66/07/Th. XX, 17 Juli 2017

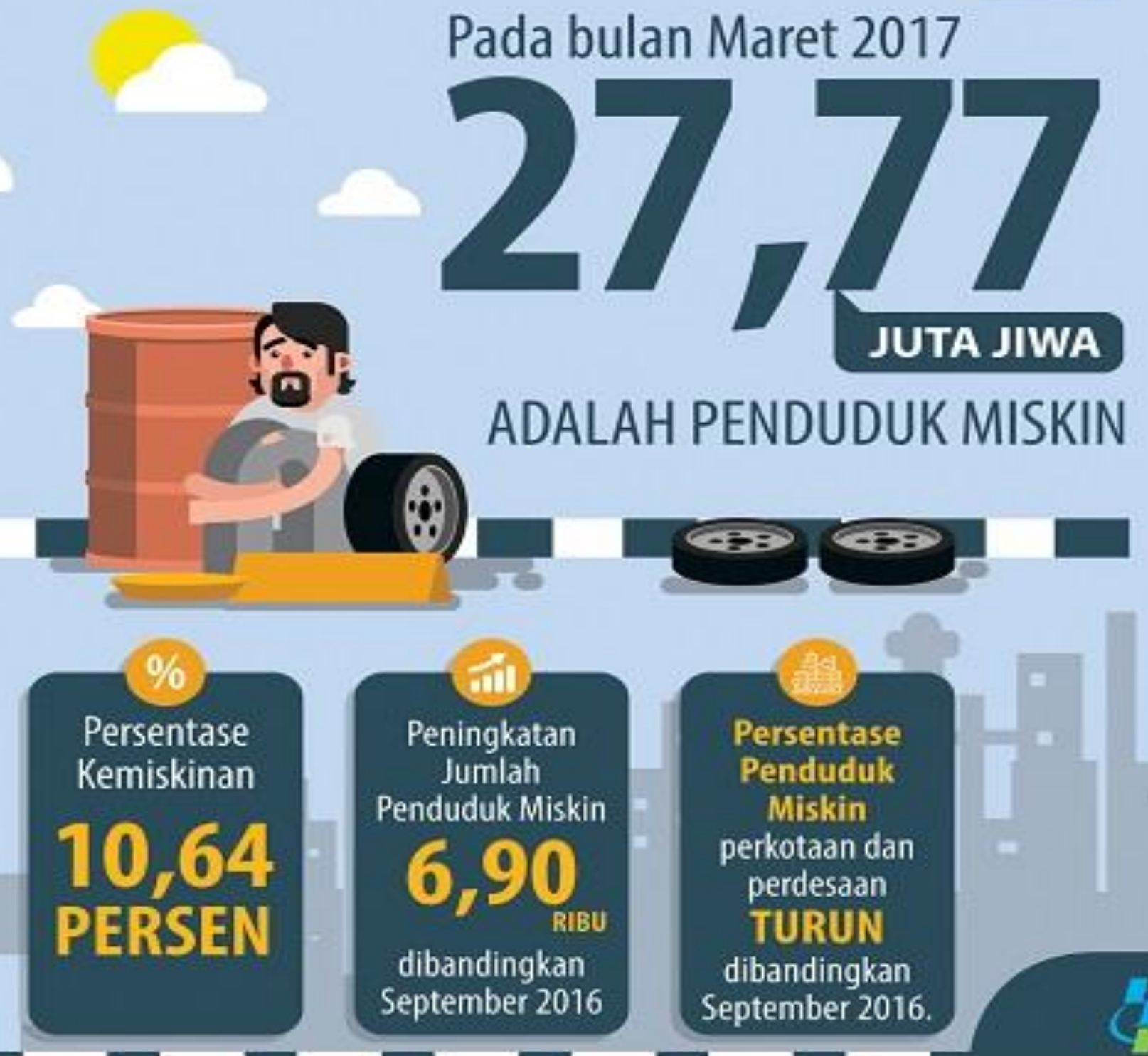

Pada bulan Maret 2017

ADALAH PENDUDUK MISKIN

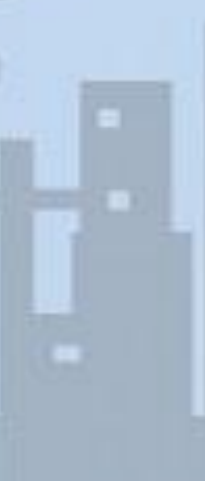

Faktor Terkait Kemiskinan

INFLASI Sep 2016-Mar 2017 sebesar 2,24\%.

INFLASI Mar 2016-Mar 2017 sebesar $3,61 \%$.

Upah Nominal Harian Buruh Tani Maret 2017 naik 2,57\%. Upah Riil Buruh Tani per hari Maret 2017 naik $0,16 \%$.

Upah Nominal Buruh Bangunan Maret 2017 naik $1,51 \%$.

Upah Riil Buruh Bangunan per hari turun $0,72 \%$.

Penurunan harga eceran beras, daging ayam ras, daging sapi, gula pasir, tepung terigu, dan telur ayam ras.

Terjadi hambatan dalam distribusi beras sejahtera (rastra).
Penduduk

\section{Miskin} erkotaan dan perdesaan TURUN September 2016. 


\section{INDONESIA MENEMPATI URUTAN KE 41 DARI 138 NEGARA \\ DALAM GLOBAL COMPETITIVENESS INDEX}

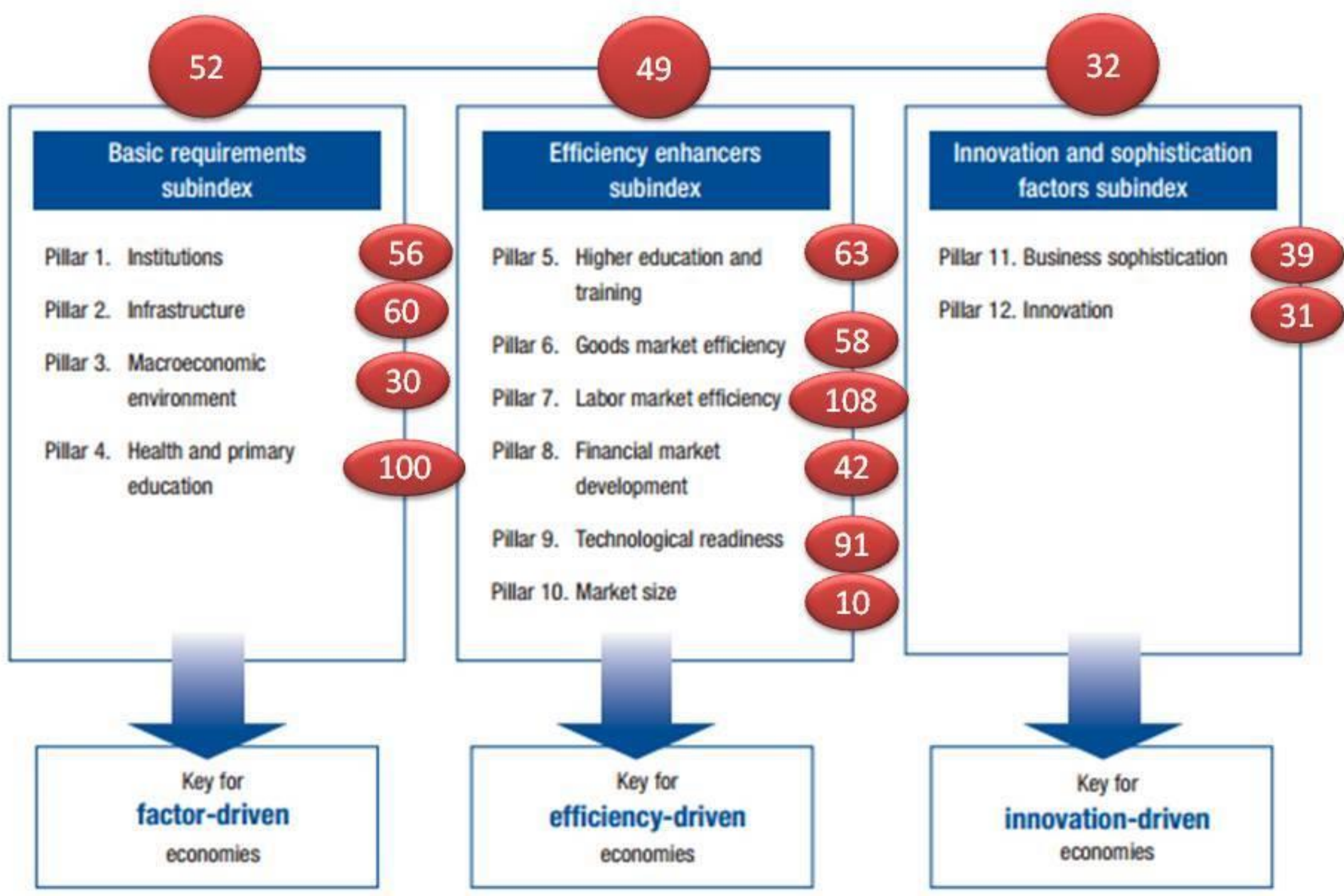








\section{PROBLEM PEMBERANTASAN KORUPSI DI INDONESIA}

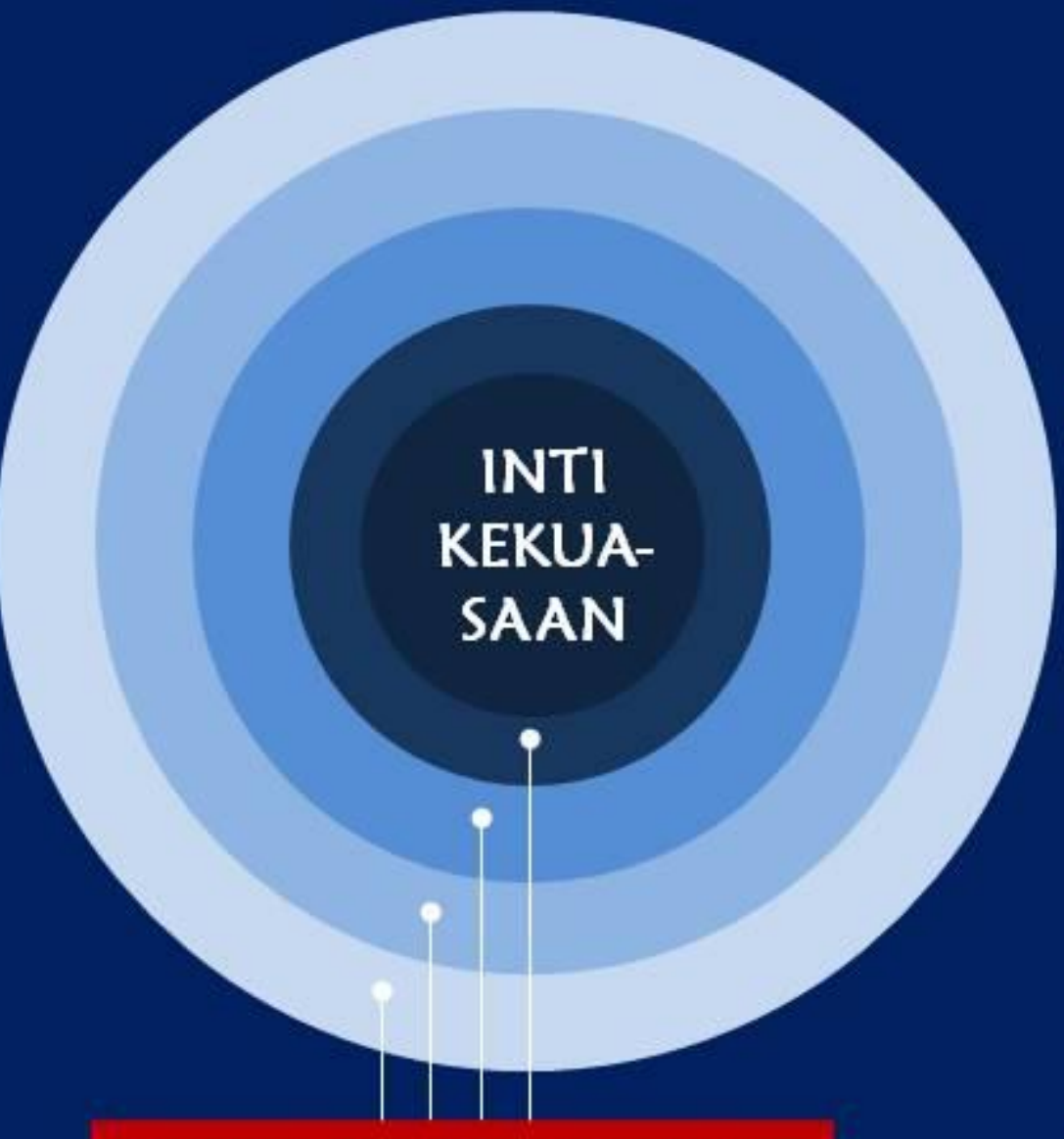

POWER TEND TO CORRUPT
LE GAL-FRAMEWORK DAN KODE ETIK SERTA TRADISI YANG BERKEMBANG AKIBAT PENENTUAN PROTAP KESUPERB ODIAN YANG SALAH KAPRAH DITOPANG OLEH AT MOSFER POUTIK YANG TIDAK SEHAT

MITOS YANG DIABADIKAN:

(-) DAERAH LEBIH KORUP DARIPADA PUSAT

(-) LEGISLATIF LEBIH KORUP DARIPADA EKSEKUTIF

(-) BIROKRAS PEMERINTAHAN LEBIH KORUP DARIPADA DUNIA USAHA

(-) OPINI UMUM LEBIHPENTING DARIPADA PRESTASI KERIA

(-) LEMBAGA PENEGAK HUKUM KONYENSIONAL DIPANDANG SEBAGAI BOROK NASIONAL
REVISI UU KPK BUKAN PADA BAGIAN REMEHTEMEH

PERBAIKI SISTEM REKRUT MEN UNTUK MENDAPATKAN ORANG YANG MEMILIKI INTEGRITAS

B A TASI USIA KPK

B ATASI MASA KERIA PIMPINAN KPK 2,5 TAHUN

TINGKATKAN BESARAN KA SUS YANG DAPAT DITANGANI KPK MENJADI

RP 5 MILYAR UP

TENTUKAN MODEL SINERGITAS DENGAN LEMBACA PENEGAK HUKUM

KONVENSIONAL

PARA PEMBANTU PRESIDEN \& LEMBA GA TINGGINEGARA

LEMBAGA PENEGAK HUKUM KONVENSIONAL

DUNIA USAHA DALAM/LUARNEGERI INCLUDE BUMN/BUMD

KEKUASAANKPK TIDAK BERSUMBER DA RI PRESIDEN MELAINKAN BERSUMBER DARJ UU 


